\title{
Study on Corrosion of Iron-Zinc Oxide Particulate Composites Produced by a Spark Plasma Sintering in Hanks' Solution
}

\author{
Miriam Kupková ${ }^{1, *}$, Martin Kupka ${ }^{2}$, Monika Hrubovčáková ${ }^{1}$, Renáta Oriňaková ${ }^{3}$, \\ Andrea Morovská Turoňová, Viktor Puchý ${ }^{1}$ \\ ${ }^{1}$ Institute of Materials Research, Slovak Academy of Sciences, Watsonova 47, SK-040 01 Košice, \\ Slovak Republic \\ ${ }^{2}$ Institute of Experimental Physics, Slovak Academy of Sciences, Watsonova 47, SK-040 01 Košice, \\ Slovak Republic \\ ${ }^{3}$ Department of Physical Chemistry, Institute of Chemistry, Faculty of Science, P.J. Šafárik \\ University, Moyzesova 11, SK-041 54 Košice, Slovak Republic \\ *E-mail: mkupkova@saske.sk
}

doi: $10.20964 / 2018.12 .57$

Received: 19 August 2018 / Accepted: 1 October 2018 / Published: 5 November 2018

\begin{abstract}
In an attempt to find an iron-based biomaterial which corrodes more rapidly than a pure iron, an ironzinc oxide particulate composite was produced by spark plasma sintering a mixture of carbonyl iron micropowder and zinc oxide nanopowder. Composite materials with a $\mathrm{ZnO}$ content of 0.5, 1.0 and 5.0 wt.\% were manufactured in this way and subsequently tested for corrosion in Hanks' solution. The composites were expected to undergo a galvanic corrosion, with $\mathrm{Fe}$ acting as the anode and semiconducting $\mathrm{ZnO}$ acting as the cathode. Due to a galvanic stimulation, a composite with the lowest content of $\mathrm{ZnO}$ actually corroded twice as fast as did a pure iron produced by a spark plasma sintering. However, in the case of galvanic corrosion and for compositions under investigation, the corrosion potential and corrosion rate of a composite could increase with increasing cathode-to-anode area ratio, that is, with increasing content of $\mathrm{ZnO}$. As the content of $\mathrm{ZnO}$ was increased, the corrosion potential indeed increased, but the corrosion current per unit area of composite surface decreased. This decrease in corrosion rate was regarded as being a consequence of a poor electric conductance of $\mathrm{ZnO}$ regions, which has led to relevant ohmic potential drops (IR drops) along the galvanic current paths through these regions. Some of possibilities to minimize IR drops and thus to maximize the corrosion rate are mentioned.
\end{abstract}

Keywords: iron based biomaterial, zinc oxide nanopowder, metal matrix composite, spark plasma sintering, corrosion in Hanks' solution

\section{FULL TEXT}


(C) 2018 The Authors. Published by ESG (www.electrochemsci.org). This article is an open access article distributed under the terms and conditions of the Creative Commons Attribution license (http://creativecommons.org/licenses/by/4.0/). 